\title{
Developing a Framework for Spatial Effects of Smart Cities Based on Spatial Econometrics
}

\author{
Kongling Liu, ${ }^{1,2,3}$ Mengjun Wang, ${ }^{1}$ Jianchang Li $\mathbb{C}^{\circ},{ }^{4}$ Jingjing Huang, ${ }^{5}$ Xuhui Huang, \\ Shuhang Chen, ${ }^{7}$ and Baoquan Cheng $\mathbb{D}^{1}$ \\ ${ }^{1}$ Department of Engineering Management, School of Civil Engineering, Central South University, Changsha, \\ Hunan 410075, China \\ ${ }^{2}$ School of Construction Engineering, Hunan Institute of Engineering, Xiangtan 411104, China \\ ${ }^{3}$ Hunan Provincial Key Laboratory of Intelligent Disaster Prevention-Mitigation and Ecological Restoration in Civil Engineering, \\ Hunan Institute of Engineering, Xiangtan 411104, China \\ ${ }^{4}$ Department of Financial Mathematics, School of Science, Xi'an Jiaotong-Liverpool University, Suzhou, Jiangsu 215123, China \\ ${ }^{5}$ Department of Building \& Real Estate, Hong Kong Polytechnic University, Hung Hom 810005, Hong Kong \\ ${ }^{6}$ School of Civil Engineering, Anhui Jianzhu University, Hefei, Anhui 230601, China \\ ${ }^{7}$ Department of Civil Engineering, Xi'an Jiaotong-Liverpool University, Suzhou, Jiangsu 215123, China
}

Correspondence should be addressed to Baoquan Cheng; curtis_ch@163.com

Received 4 May 2021; Accepted 1 June 2021; Published 12 June 2021

Academic Editor: Shaohui Wang

Copyright $\odot 2021$ Kongling Liu et al. This is an open access article distributed under the Creative Commons Attribution License, which permits unrestricted use, distribution, and reproduction in any medium, provided the original work is properly cited.

\begin{abstract}
The rapid urbanization in China has already put heavy pressures on imperfect infrastructure, especially for fundamental urban functions such as power and water supply, traffic, education, and healthcare. The emergence of smart cities can help cope with the rapidly expanding demands on urban infrastructure. However, the development of smart cities in China is just in its infancy, and there is still a lack of clear understanding of the development path of smart cities. This article focuses on the development of smart cities in China. It aims to (a) judge whether there is spatial autoregression in the construction of smart cities in 83 Chinese cities and (b) identify key influencing factors in the development of smart cities in China through a spatial econometric model developed by GeoDa software. The results show that there exists spatial autoregression in the development of smart cities in China. Four key influencing factors (governmental support, innovative level, economic development, and human capital) are identified. Based on these findings, suggestions for future promoting development of smart cities in China are put forward. This research can deepen the understanding of the spatial effects of smart cities and provide valuable decision-making references for policy makers.
\end{abstract}

\section{Introduction}

With the unprecedented urbanization worldwide, many serious problems such as environmental pollution, crowded housing, and traffic congestion have emerged in cities due to extensive growth patterns. Thus, many cities are suffering from mega-urban diseases $[1,2]$. Developing smart cities provides an efficient method to address mega-urban diseases and achieve the sustainable urban development [3-5]. The concept of smart cities was first proposed by International Business Machines Corporation (IBM) in 2008 [6]. It is an advanced form of informational cities with the deep integration of informatization, industrialization, and urbanization $[7,8]$. Its essence is an urban information system including five levels of natural environment, infrastructure, resources, services, and social systems $[9,10]$. It is a participatory approach for urban governance that provides a high quality of life for the public [11], which can be achieved through human and social capital.

The development of smart cities generally experiences three stages [12, 13] (Figure 1). The period from 1980s to 2008 , about 30 years, is the embryonic stage that implicitly goes from the initial elements of smart cities to the gradual completion of each element. Some cities consciously applied 


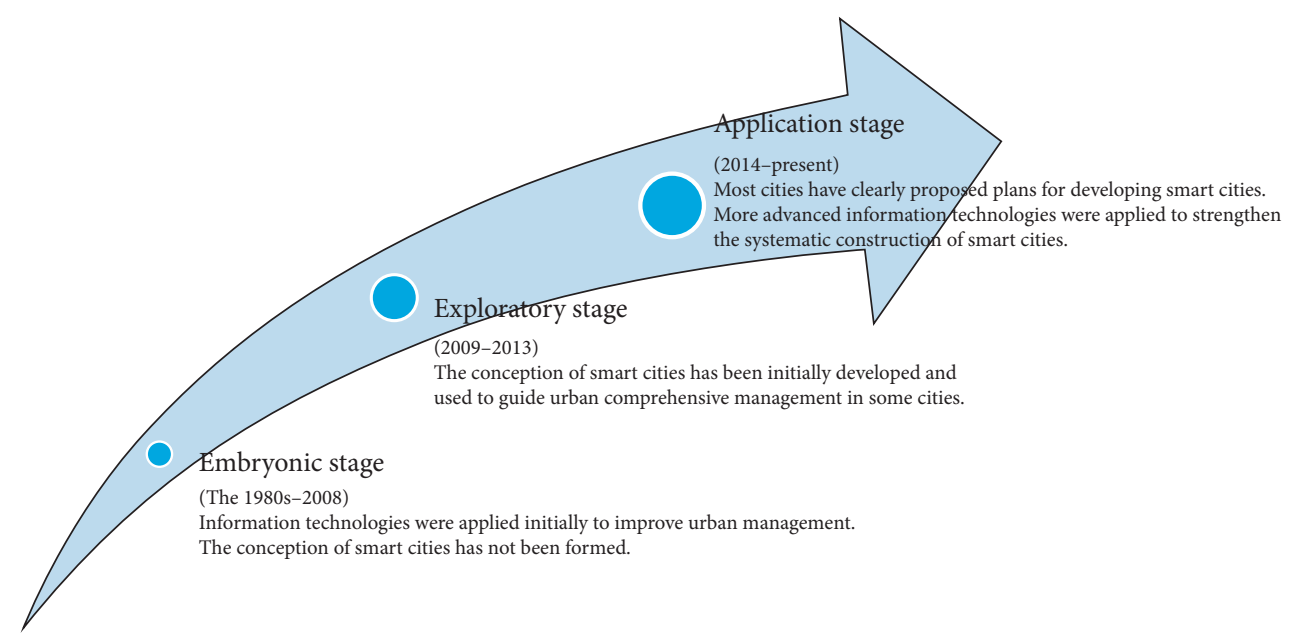

Figure 1: Development of the conception of smart cities.

information technologies such as the local area network (LAN) and Internet into some aspects of urban management to improve the efficiency. However, the integrated concept of smart cities has not yet been formed. The second stage is the exploratory stage between 2009 and 2013. With the development of information technologies in this stage, many cities explored the application of new technologies such as cloud computing, the 3rd generation telecommunication, and mobile equipment applications to strengthen integrated application and intelligent processing of urban information. At the same time, the concept of smart cities was initially developed and provided a guideline for urban planning and management. Since 2014, the concept of smart cities has been further deepened and considered as an ideal form of cities. Meanwhile, information technologies got great advancements. Advanced technologies such as Internet of Things, artificial intelligence, and big data have changed people's lives and the world $[14,15]$. Most cities have proposed clear plans to build smart cities [16-18]. This means the application stage is coming.

The deep understanding of key influence factors and development modes is fundamental to the future development of smart cities and has attracted the attention of scholars around the world. Yang et al. [19] predicated freight volume in one city based on the Markov algorithm, and this is meaningful to smart cities' development. Kourtit et al. [20] demonstrated that Information Communication Technologies play a significant role in developing smart cities. Kim et al. [21] suggested that the new Internet of Things (IoT) technology is promoting the development of the smart cities. Qian et al. [22] applied the BP neural network algorithm to optimize the allocation of taxi resource at the airport which can drive the development of the smart cities. Yang et al. [23] adopted virtual input-output approach to determine the critical nodes in traffic networks to allocate resource effectively in smart cities.

$\mathrm{Hu}$ and Chen [24] did an empirical research in China and found that differences in natural, cultural, political, economic, and other conditions result in differences in development levels of smart cities. According to Wang et al.'s study [25], the development of smart cities requires not only the development of technologies but also the advancement in management modes. It is necessary to establish a collaborative mechanism of decision-making, real-time response, and coordinated operation to truly realize the integrated management in smart cities. Previous studies have investigated the key influence factors and development modes of smart cities from different perspectives including economy, management, technologies, and policies [26-29]. However, few studies have focused on spatial effects of smart cities. In fact, there are obvious spatial differences in the development of smart cities. Therefore, it is significant and innovative to investigate spatial effects of smart cities.

This study aims to explore the spatial effects of smart cities through an empirical research in China. A spatial econometric model is developed and applied to conduct a spatial autoregressive analysis on the development levels of smart cities for 83 cities in China. Based on the autoregressive analysis, the key driving factors of developing smart cities are identified. Meanwhile, it can explore the development level of smart cities in different regions of China. This research can not only enrich the knowledge system of smart cities but also provide decision-making references for urban management.

\section{Research Methodology}

2.1. Overview. Spatial econometrics is a branch of econometrics. Compared with traditional econometric methods, it takes more spatial effects into account in the regression model of cross-sectional data and panel data $[29,30]$. Spatial effects can be classified into spatial dependence and spatial heterogeneity, in which spatial dependence reflects the correlation of spatial structure and spatial heterogeneity describes differences of different economic individuals. Spatial effects are structural features which are expressed in the form of model functions or parameters [31]. Almost all spatial data are spatially dependent, which breaks the basic assumption of independence in traditional econometrics. Therefore, in the case of cross-section data 
and panel data involving spatial problems, the spatial econometric analysis method should be adopted to make the model establishment more accurate. The combination of spatial econometrics and geographic information system (GIS) has been widely used in the economic policy analysis, especially in real estate and real estate economics, environmental and resource economics, and development economics. The spatial econometric method can well investigate the current construction situation of smart cities and predict the development trend from the perspective of geographic space. Therefore, this study applies the spatial econometric method to evaluate the spatial effects of smart cities in China.

The spatial econometric method to study the spatial effects of smart cities follows four steps. First, the key factors influencing the development of smart cities, namely, explained variables and explanatory variables, are identified and sample data are collected. Second, Moran index is used for analyzing spatial correlation of explained variables. After that, by introducing the spatial dependence based on the classical linear regression model, the corresponding spatial econometric model is established. Finally, policy suggestions are provided according to future discussions of analysis results from the spatial econometric model.

\subsection{Database Development}

2.2.1. Sample Descriptions. As shown in Figure 2, 83 cities in China have been selected for the empirical study. These cities are chosen for two reasons: one is that these cities are preventive smart cities in China. These cities have paid many efforts to develop smart cities although their development levels are different, and the development results are relatively advanced in China. The other one is that these cities are distributed throughout China, with at least one city from each province selected. In other words, this allows for a more representative and diverse selection of cities in terms of geographical distribution. The selection principle helps to better analyze and explain the spatial effects of smart cities in China.

\subsubsection{Indicator Selection}

(1) Explained Variable. The explained variable is the development level of different cities, which is represented by SCORE in the model. It is quantified according to "Rank and score of comprehensive impact assessment of construction and development of new smart cities in China, 2017-2018" released by China Network on July 31, 2018 [32]. This list could evaluate Chinese cities based on the requirements of the National New Smart Cities Evaluation Program. This indicator score adopts the hundred-mark system. The higher the score, the higher the level of smart city.

(2) Explanatory Variables. Four explanatory variables are selected in this study as follows:

(1) Government's livelihood policy support
The government's livelihood policy support is measured by the local general budget expenditure of the municipal government in 2017 and expressed by EXP in the model formula. The general budget expenditure of the local government is the part related to people's livelihood in local financial expenditure, such as education, social security and employment, medical and healthcare, environmental protection, urban and rural community affairs, agriculture, forestry and water affairs, and transportation. The construction of smart city is people-oriented and focuses on the convenient services that can be perceived by the public. The local general budget expenditure can be closely related to the quality of life of citizens.

(2) Innovation level

The innovation level is measured by the number of practical patent authorization of the city in 2017 and expressed by PA in the model. This indicator represents the material basis of smart cities relying on sophisticated technologies such as the trinetwork interconnection, artificial intelligence, and information and communication technology and reflects the innovation vitality of a city.

(3) Economic basis

The economic basis is measured by the gross domestic product of the whole city in 2017 and expressed by GDP in the model. The construction of smart cities requires a large amount of financial investment, and there should also be a certain relationship between the economic basis and the development level of smart cities.

(4) Level of human capital

The level of human capital is measured by the number of full-time academic staffs in institutions of higher learning in 2017 and expressed by TEA in the model. This indicator is selected because talents are the reserve force for the construction of smart cities.

Statistic data are obtained from the Statistical Bulletin of National Economic and Social Development of 2017, the Statistical Yearbook of 2018, and the Statistical Yearbook of Chinese cities of 2018. Spatial coordinates of cities are obtained from Google Maps. On this basis, the original collected data are standardized to eliminate order of magnitude differences.

2.3. Spatial Autocorrelation Test. The spatial autocorrelation test is divided into the global spatial autocorrelation test and local spatial autocorrelation test.

2.3.1. Global Spatial Autocorrelation Test. In this study, Moran's $I$ index is adopted for the global spatial autocorrelation test. The value range of Moran's $I$ statistic is $[-1,1]$. A value less than 0 means a negative correlation, and the closer to -1 means a greater difference between units or a less-concentrated distribution. A value greater than 0 


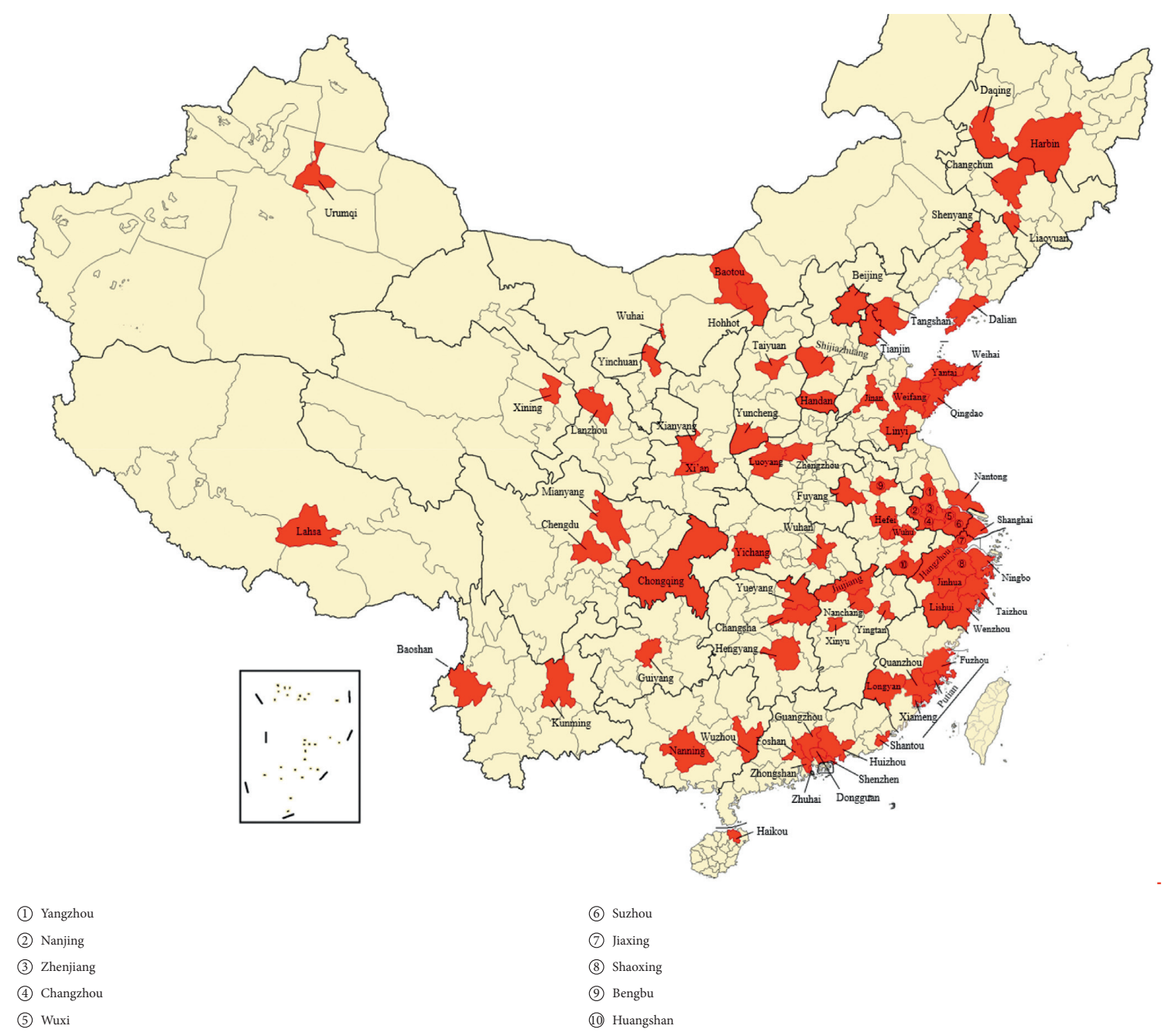

Figure 2: 83 smart cities in China.

indicates a positive correlation and closer to 1 indicates the more similar the properties are. A value equal to zero means it does not matter. It can be calculated through

$$
\text { Moran's } I=\frac{\sum_{i=1}^{n} \sum_{j=1}^{n} W_{i j}\left(Y_{i}-\bar{Y}\right)}{S^{2} \sum_{i=1}^{n} \sum_{j=1}^{n} W_{i j}},
$$

in which, $S^{2}$ and $Y$ can be calculated through equations (2) and (3):

$$
\begin{aligned}
& S^{2}=\frac{1}{n} \sum_{i=1}^{n}\left(Y_{i}-\bar{Y}\right), \\
& Y=\frac{1}{n} \sum_{i=1}^{n}\left(Y_{i}\right),
\end{aligned}
$$

where $Y_{i}$ represents the observed value of each variable in region $i . n$ is the total number of cities, that is, 83 in this study. $W_{i j}$ is the binary neighborhood space weight matrix, representing the distance proximity relationship between city $i$ and city $j . X_{i}$ and $X_{j}$ are the attributes of region $I$ and region $j$, respectively, and are the attribute mean value of the attributes. $S_{2}$ is the variance of the attributes.
2.3.2. Local Spatial Autocorrelation Test. Moran scatter plot is selected for the local spatial autocorrelation test in this study. Moran scatter diagram takes $\left(W_{z}, z\right)$ as the coordinate point and thus visualizes the two-dimensional representation of spatial lag factors $W_{z}$ and $z$. The first and third quadrants of Moran scatter plot represent the positive spatial correlation of observed values, while the second and fourth quadrants represent the negative spatial correlation of observed values. GeoDa software can be used to draw the Moran scatter plot.

2.4. Spatial Econometric Model. The classical linear regression model can be expressed by

$$
\begin{aligned}
\operatorname{LnSCORE}= & \beta_{0}+\beta_{1} \operatorname{LnEXP}+\beta_{2} \operatorname{LnPA}+\beta_{3} \operatorname{LnGDP} \\
& +\beta_{4} \operatorname{LnTEA}+\varepsilon,
\end{aligned}
$$

where $\beta_{0}$ is a constant term, $\beta_{i}$ is the regression coefficient, and $\varepsilon$ is a random error term.

The spatial lag model (SLM) and spatial error model (SEM) are two basic models which take spatial effects into consideration based on the classical linear regression model. The SLM can analyze the influence of explanatory variables 
of adjacent regions on the explained variable in this region, that is, the spatial spillover effect. The SEM can simulate the impacts of the error of explanatory variables in adjacent regions on the explained variable in this region. They can be expressed by equation (5) and equation (6), respectively.

$$
\begin{aligned}
\operatorname{LnSCORE}= & \beta_{0}+\rho W_{i j} \operatorname{LnSCORE}+\beta_{1} \operatorname{LnEXP}+\beta_{2} \operatorname{LnPA} \\
& +\beta_{3} \operatorname{LnGDP}+\beta_{4} \operatorname{LnTEA}+\varepsilon,
\end{aligned}
$$

where $\rho$ is the spatial autoregression coefficient; $W_{i j}$ is the spatial weight matrix of order $n \times n ; W_{i j}$ LnSCORE is the explained variable of spatial lag; $\varepsilon$ is the random error term vector; and $\varepsilon \sim N\left[0, \sigma_{2}\right]$.

$$
\begin{aligned}
\operatorname{LnSCORE}= & \beta_{0}+\beta_{1} \operatorname{LnEXP}+\beta_{2} \operatorname{LnRD}+\beta_{3} \operatorname{LnGDP} \\
& +\beta_{4} \operatorname{LnTEA}+\varepsilon,
\end{aligned}
$$

where $\varepsilon$ is the random error term vector which can be calculated through

$$
\varepsilon=\lambda W_{i j} \varepsilon \pm \mu,
$$

where $\lambda$ is the coefficient of spatial error of the cross-sectional dependent variable vector of order $n \times 1$. It measures the spatial dependence of the observed values of the samples. $\mu$ is the random error vector with normal distribution.

\section{Results and Discussion}

3.1. Spatial Autocorrelation Test. Table 1 provides the results of the global spatial autocorrelation test. It can be seen that Moran's I index of the development level of smart cities and the level of human capital pass the hypothesis test of $1 \%$ significance level. Other variables including government's livelihood policy support, innovation level, economic basis, and level of human capital pass the hypothesis test of 5\% significance level. This indicates that there exists obvious spatial autocorrelation in the development level of smart cities and their influence factors. In other words, the degree of smart development of a city can be affected by the development of adjacent cities. Therefore, the classical econometric model ignoring spatial effects is not suitable to analyze the development of smart cities.

Figure 3 shows the Moran scatter plot of the smart development levels of 83 cities drawn by GeoDa software, and the results of the local spatial autocorrelation test are given in Table 2. It can be learnt that most cities are concentrated in the first and third quadrants, indicating that there is an obvious positive spatial correlation. This means that the smart cities which are growing well are close to each other, while the cities lagging in smart city development are similarly far away. Specifically, the southeast coastal areas of China, such as Jiangsu and Zhejiang regions and the Pearl River Delta region, are developing fast in smart cities construction. The western regions, such as Tibet, Xinjiang, and Gansu, have seen slower development of smart cities. Some leading cities in the central region, such as Wuhan and Hefei, have also developed smart cities that deserve praise. Cities in low-high agglomeration areas are close to developed smart cities in geographical distance, but their own development level is relatively slow, which can be regarded as the depression area. Future research is needed to explain the reason for this phenomenon. On the other hand, some cities are close to behindhand cities, but their own development level of smart cities is excellent, which can be regarded as the pole area. This is because core cities with dominant positions can attract resource elements from surrounding small and medium-sized cities and towns. This phenomenon can be called the siphon effect. For example, as the capital of China, the development level of smart cities of Beijing is ahead of other cities in North China.

3.2. Spatial Econometric Analysis. Table 3 provides the results of classical linear regression based on cross-section data in 2017. The calculation is conducted through GeoDa software. Moran's I test of residuum, the LMERR test and LMLAG of two Lagrange multipliers, and the R-LMLAG test and R-LMERR test of robust forms are also conducted to judge which spatial econometric is applied. It can be found that the goodness-of-fit of the classical regression model is not high, and thus, the spatial econometric model should be adopted. In addition, the LMLAG test $(p=0.07491)$ is more significant than the LMERR test ( $p=0.51446)$. At the same time, the R-LMLAG test passes the hypothesis test of 5\% significance level $(p=0.04750)$, while the R-LMERR test is not significant ( $p=0.27722)$. It can be judged that the SLM model is more suitable for reflecting spatial effects of the development of smart cities in China.

Table 4 provides the results of spatial econometric regression with the SLM model based on cross-section data in 2017. Compared with the classical linear regression, its value of $\log$ likelihood is larger, while the values of AIC and SC are smaller. This strongly proves that the development of smart cities in each city interacts spatially, which confirms the validity of the chosen spatial econometric model. The absolute value of coefficient of the SLM model is slightly smaller than that of the classical linear regression model, which indicates that the spatial econometric model corrects the promotion or restriction effects of various influencing factors on the development of smart cities. The coefficient of the spatial lag variable is positive and large, which reflects that the development of smart cities in China has agglomeration phenomenon in spatial distribution, and the spatial spillover effect is obvious. The regression coefficient of the number of practical patent authorization of the city is the largest, and it passes the hypothesis test of $1 \%$ significance level, indicating that the high-precision technology plays a key role in the development of smart cities. The regression coefficient of the local general budget expenditure is relatively large, and it also passes the hypothesis test, suggesting that the government's policy support contributes to the development of smart cities, where financial support related to people's lives and livelihood services is more beneficial to the construction of smart cities than other financial investments. It is noted that the regional annual gross domestic product (GDP) does not have a significant explanatory power in the model. This demonstrates that the 
TABLE 1: Results of the global spatial autocorrelation test.

\begin{tabular}{lccccr}
\hline Variable & Moran's $I$ & $E(I)$ & Sd. & $Z$ value & $P$ value \\
\hline LnSCORE & 0.2831920 & -0.0122 & 0.0658 & 4.5604 & 1.9870 \\
LnEXP & 0.0998765 & -0.0122 & 0.0610 & 2.0545 & 0.025 \\
LnPA & 0.1148820 & -0.0122 & 0.0625 & 3.0992 & 0.025 \\
LnTEA & 0.2014100 & -0.0122 & 0.0684 & 0.002 \\
LnGDP & 0.1054040 & -0.0122 & 0.0633 & 1.9968 & 0.038 \\
\hline
\end{tabular}

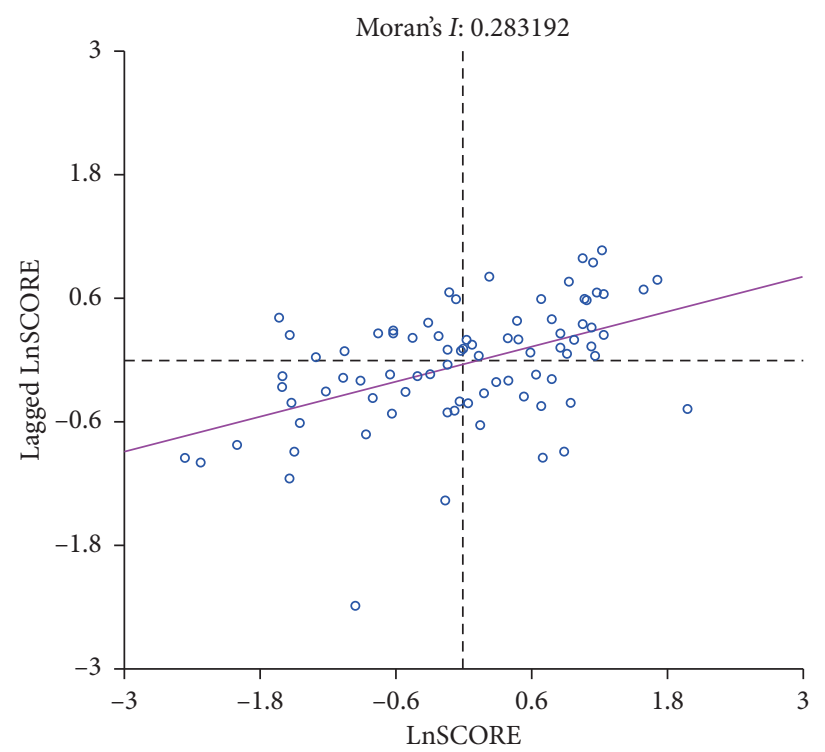

Figure 3: Moran scatter plot of the development level of smart cities of 83 cities.

TABLE 2: Results of local spatial autocorrelation.

\begin{tabular}{|c|c|}
\hline Spatial correlation mode & Region \\
\hline $\begin{array}{l}\text { High-high concentration } \\
\text { (HH) }\end{array}$ & $\begin{array}{c}\text { Shenzhen, Guangzhou, Shanghai, Hangzhou, Chongqing, Ningbo, Wuhan, Tianjin, Nanjing, Xiamen, Xi’an, } \\
\text { Changsha, Suzhou, Dongguan, Wenzhou, Wuxi, Yichang, Foshan, Changzhou, Zhuhai, Jiaxing, Yueyang, } \\
\text { Hefei, Wuhu, Zhongshan, Shantou, Weihai, Taizhou, Nantong, Liaoyuan, Luoyang, and Huizhou }\end{array}$ \\
\hline $\begin{array}{l}\text { Low-high concentration } \\
\text { (LH) }\end{array}$ & $\begin{array}{l}\text { Shijiazhuang, Hohhot, Zhenjiang, Shaoxing, Yangzhou, Hengyang, Putian, Yantai, Tangshan, Lishui, } \\
\text { Huangshan, Yuncheng, Zhangzhou, and Daqing }\end{array}$ \\
\hline $\begin{array}{l}\text { Low-low concentration } \\
\text { (LL) }\end{array}$ & $\begin{array}{c}\text { Jinan, Changchun, Nanchang, Yinchuan, Haikou, Urumqi, Kunming, Nanning, Lanzhou, Lhasa, Xining, } \\
\text { Xianyang, Weifang, Mianyang, Yi, Jiujiang, Baotou, Longyan, Fuyang, Baoshan, Yingtan, Wuhai, Xinyu, and } \\
\text { Linyi }\end{array}$ \\
\hline $\begin{array}{l}\text { High-low concentration } \\
\text { (HL) }\end{array}$ & $\begin{array}{c}\text { Beijing, Chengdu, Harbin, Dalian, Shenyang, Qingdao, Guiyang, Fuzhou, Zhengzhou, Taiyuan, Jinhua, } \\
\text { Quanzhou, and Ningbo }\end{array}$ \\
\hline
\end{tabular}

TABLE 3: Results of classical linear regression based on cross-section data in 2017.

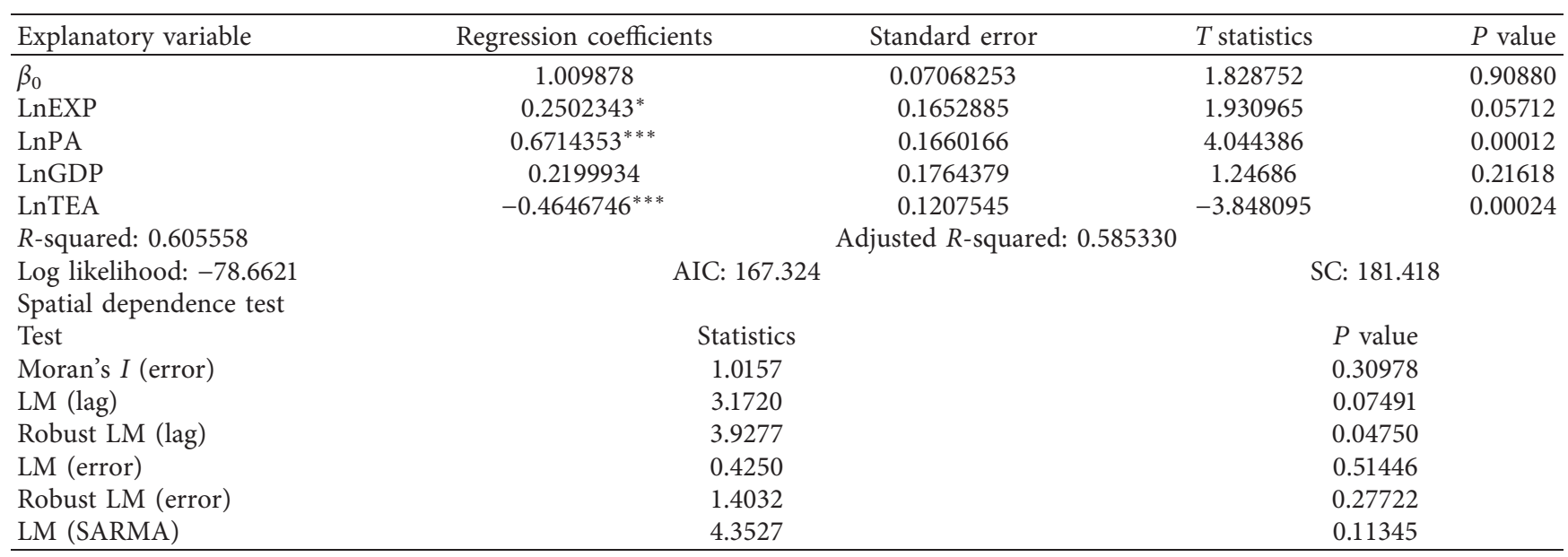

Note. ${ }^{* * *},{ }^{* *}$, and ${ }^{*}$ indicate the significance test at $1 \%, 5 \%$, and $10 \%$, respectively. 
TABLE 4: Results of spatial econometric regression based on crosssection data in 2017.

\begin{tabular}{|c|c|c|c|}
\hline $\begin{array}{l}\text { Explanatory } \\
\text { variable }\end{array}$ & $\begin{array}{l}\text { Regression } \\
\text { coefficients }\end{array}$ & $Z$ value & $P$ value \\
\hline$\beta_{0}$ & 0.089859 & 0.129894 & 0.89665 \\
\hline W-LnSCORE & $0.2140779^{*}$ & 1.744983 & 0.08099 \\
\hline LnEXP & $0.2334007^{*}$ & 1.851803 & 0.06405 \\
\hline LnPA & $0.5856314^{* * *}$ & 3.57673 & 0.00035 \\
\hline LnGDP & 0.1965981 & 1.172502 & 0.24100 \\
\hline LnTEA & $-0.3640897^{* * *}$ & -2.898652 & 0.00375 \\
\hline Statistics test & & & \\
\hline$R$-squared: 0.622755 & & & \\
\hline $\begin{array}{l}\text { Log likelihood: } \\
-77.1914\end{array}$ & \multicolumn{2}{|c|}{ AIC: 166.383} & $\begin{array}{c}\text { SC: } \\
180.896\end{array}$ \\
\hline
\end{tabular}

development of smart cities should not be solely based on the economic development but should be flexible in policy means, so that the development of smart cities can really benefit citizens. Meanwhile, the number of full-time academic staffs in institutions of higher learning is inversely proportional to the development level of smart city construction, which seems contrary to the common sense. In fact, this result indicates that the quality of human capital should not be ignored. When recruiting staffs, attention should be paid not only to the quantity but also to the quality, so that the level of human capital can be improved.

3.3. Limitation of This Study. In general, the fitting degree of 0.62 of this developed model in this study is not quite satisfactory. There are three main reasons. First, only one year's statistical data and four indicators are selected, which lead to a slight limitation in the analysis results. Second, the development of smart cities has just started in China, and the sample size of smart cities is not quite large. At last, the effect of smart city development is lagging. This means that it takes some time for changes in the influencing factors in recent years to be gradually reflected in the development level of smart cities. Although there are some defects in the fitting of the model, it can still provide some references for the development of smart cities.

\section{Conclusions and Recommendations}

This study develops a spatial econometric model to investigate spatial effects of development of smart cities. 83 representative smart cities in China are selected for the empirical study. The development level of smart cities is set as the explained variable, and the government's livelihood policy support, innovation level, economic basis, and level of human capital are selected as explanatory variables. Then, the spatial autocorrelation analysis is conducted. A SLM model is also established, and the results are compared with the classical linear regression model. It can be found that the development of smart cities in the southeast coastal area is relatively high in China, and the agglomeration type is mostly the high-level development type of high-high concentration and high-low concentration. The spillover effect is obvious, which indicates that the geographical proximity between cities can promote economic, cultural, scientific, and technological exchanges between cities and share the development achievements of smart cities.

With the strong support of the government, the central cities have absorbed the advanced experience of the southeast coastal cities, and the construction of smart cities has also gradually risen. Due to the lack of resources and power to build smart cities, Western cities still need to explore their development paths. It can be also found that the siphon effect would occur when the size of the central city is huge, and the gap between surrounding cities is quite large. The central city should accelerate innovation and transformation and carry out necessary functional disarrangement to promote the spillover effect and drive the development of surrounding smart cities with radiation.

In addition, the government's livelihood policy support, innovation level, economic basis, and level of human capital all play an important role in the construction of smart cities to varying degrees. The effects of some factors can only be reflected gradually after a certain period of accumulation. The findings from this study can deepen the understanding of the spatial effects of the smart city development and provide references for future urban planning and management. However, the samples of 83 cities are still limited. In the future, more indicators and data should be collected to further validate the developed model.

\section{Data Availability}

The data used to support the findings of this study are included within the article.

\section{Conflicts of Interest}

The authors declare that they have no conflicts of interest.

\section{Acknowledgments}

The authors acknowledge the financial support from the 13th Five-Year National Key Research and Development Plan, China (2017YFB1201204), China Innovation Funding, the National Natural Science Foundation of China (71942006), and the Natural Science Foundation of Hunan Province, China (2019JJ40407).

\section{References}

[1] R. Sheng and S. L. Liu, "Evolution on regional disparities in China from 2000 to 2012: evidence from 74 cities within three mega-urban regions along Yangtze river," Quality \& Quantity, vol. 52, no. 5, pp. 1989-2006, 2018.

[2] S. Shi, "Measurement index system and empirical analysis of China's urban diseases," Economic Geography, vol. 34, no. 10, pp. 1-6, 2014.

[3] Y. Guo, Z. Tang, and J. Guo, "Could a smart city ameliorate urban traffic congestion? A quasi-natural experiment based on a smart city pilot program in China," Sustainability, vol. 12, no. 6, p. 2291, 2020. 
[4] H. Haarstad and M. W. Wathne, "Are smart city projects catalyzing urban energy sustainability?" Energy Policy, vol. 129, pp. 918-925, 2019.

[5] R. Papa, C. Gargiulo, and A. Galderisi, "Towards an urban planners' perspective on smart city," TeMA: Journal of Land Use, vol. 6, no. 1, pp. 5-17, 2013.

[6] F. Wang, Z. Xu, Z. Qiu, W. Ni, J. Li, and Y. L. Luo, "Algorithm for target detection in smart city combined with depth learning and feature extraction," Wireless Communications and Mobile Computing, vol. 2020, Article ID 8885670, 7 pages, 2020.

[7] B. N. Silva, M. Khan, and K. Han, "Towards sustainable smart cities: a review of trends, architectures, components, and open challenges in smart cities," Sustainable Cities and Society, vol. 38, pp. 697-713, 2018.

[8] M. Aribilosho and A. Usoro, "A review on smart cities: impact of technology and social factors," Computing \& Information Systems, vol. 20, no. 1, pp. 21-28, 2016.

[9] R. W. S. Ruhlandt, "The governance of smart cities: a systematic literature review," Cities, vol. 81, pp. 1-23, 2018.

[10] P. G. Viale, P. Peter, F. Enzo, and K. Reinout, "Smart governance in the context of smart cities: a literature review," Information Polity, vol. 23, no. 2, pp. 1-20, 2018.

[11] J. Macke, R. M. Casagrande, J. A. R. Sarate, and K. A. Silva, "Smart city and quality of life: citizens' perception in a Brazilian case study," Journal of Cleaner Production, vol. 182, pp. 717-726, 2018.

[12] C. Wang, Towards the Smart City of Excellence-Based on the Global Smart City Construction Case Study, Shanghai Academy of Social Sciences Press, Shanghai, China, 2017.

[13] E. R. Sanseverino, R. R. Sanseverino, V. Vaccaro, I. Macaione, and E. Anello, "Smart cities atlas," in Smart Cities: Case StudiesSpringer International Publishing, Berlin, Germany, 2017.

[14] M. Rawashdeh and A. Alnusair, "Models for multimedia mobile cloud in smart cities," Multimedia Systems, vol. 25, no. 5, pp. 525-534, 2019.

[15] N. Lopes and S. Coelho, "Data analytics tool for smart cities," Current Medicinal Chemistry, vol. 6, no. 2, pp. 84-92, 2017.

[16] J. Wang, J. Zhao, Y. Zhang, X. Peng, Y. Li, and Y. Xie, "Enabling human-centric smart cities: crowdsourcing-based practice in China," Computer, vol. 51, no. 12, pp. 42-49, 2018.

[17] G. Maccani, B. Donnellan, and M. Helfert, Action Design Research in Practice: The Case of Smart CitiesSpringer International Publishing, Berlin, Germany, 2014.

[18] K. Mustapha, H. Mcheick, and S. Melouli, "Smarter as the new urban agenda," in Smart Cities and Resilience Plans: a MultiAgent Based Simulation for Extreme Event RescuingSpringer International Publishing, Berlin, Germany, 2016.

[19] F. Yang, X. Y. Tang, Y. X. Gan, X. D. Zhang, J. C. Li, and $\mathrm{X}$. Han, "Forecast of freight volume in Xi'an based on gray GM $(1,1)$ model and Markov forecasting model," Journal of Mathematics, vol. 2021, Article ID 6686786, 6 pages, 2021.

[20] K. Kourtit, P. Nijkamp, and J. Steenbruggen, "The significance of digital data systems for smart city policy," Socio-Economic Planning Sciences, vol. 58, pp. 13-21, 2017.

[21] T.-h. Kim, C. Ramos, and S. Mohammed, "Smart city and IoT,” Future Generation Computer Systems, vol. 76, pp. 159162, 2017.

[22] Y. M. Qian, S. H. Chen, J. C. Li et al., "A decision-making model using machine learning for improving dispatching efficiency in Chengdu Shuangliu airport," Complexity, vol. 2020, Article ID 6626937, 16 pages, 2020.
[23] F. Yang, F. Yan, C. K. Zhang et al., "Applying the virtual input-output method to the identification of key nodes in busy traffic network," Complexity, vol. 2021, Article ID 5559857, 7 pages, 2021.

[24] L. Hu and Y. F. Chen, "Risk performance and countermeasures in different stages of smart city construction," China Population Resources and Environment, vol. 23, no. 11, pp. 130-136, 2013.

[25] G. B. Wang, L. Zhang, and H. L. Liu, "Theoretical research and practical thinking of smart cities at home and abroad," Science and Technology Progress and Countermeasures, vol. 30, no. 19, pp. 153-160, 2013.

[26] N. Zhang, X. Y. Chen, and G. Song, "Empirical research on key issues in the development of smart cities in China," Urban Development Research, vol. 22, no. 6, pp. 27-33, 2015.

[27] S. Caird, "City approaches to smart city evaluation and reporting: case studies in the United Kingdom," Urban Research \& Practice, vol. 11, no. 2, pp. 159-179, 2018.

[28] S. Ben Letaifa, "How to strategize smart cities: revealing the SMART model," Journal of Business Research, vol. 68, no. 7, pp. 1414-1419, 2015.

[29] L. Anselin, "Spatial econometrics: methods and models," Journal of the American Statistical Association, vol. 85, no. 411, p. 160, 1990.

[30] R. Bivand and G. Piras, "Comparing implementations of estimation methods for spatial econometrics," Journal of Statistical Software, vol. 63, no. 18, pp. 1-36, 2015.

[31] B. Roberto, D. Maria, M. Roman, M. M. Jose, and M. Jesús, "Modeling regional economic dynamics: spatial dependence, spatial heterogeneity and nonlinearities," Journal of Economic Dynamics \& Control, vol. 48, pp. 229-245, 2014.

[32] L. X. Sun, "Rank and score of comprehensive impact assessment of construction and development of new smart cities in China, 2017-2018," 2018, http://guoqing.china.com.cn/ 2018-07/31/content_57910725_5.htm. 